\title{
Developments to Increase the Performance, Operational Versatility and Automation of a Lunar Surface Manipulation System
}

\author{
John T. Dorsey ${ }^{1}$, Thomas C. Jones ${ }^{2}$, William R. Doggett ${ }^{3}$, and Carlos M. Roithmayr ${ }^{4}$ \\ NASA Langley Research Center, Hampton, VA 23681 \\ Bruce D. King ${ }^{5}$ \\ Lockheed Martin Mission Services, Hampton, VA 23681 \\ and \\ Martin M. Mikulas ${ }^{6}$ \\ National Institute of Aerospace, Hampton, VA 23681
}

\begin{abstract}
The objective of this paper is to describe and summarize the results of the development efforts for the Lunar Surface Manipulation System (LSMS) with respect to increasing the performance, operational versatility, and automation. Three primary areas of development are covered, including; the expansion of the operational envelope and versatility of the current LSMS test-bed, the design of a second generation LSMS, and the development of automation and remote control capability. The first generation LSMS, which has been designed, built, and tested both in lab and field settings, is shown to have increased range of motion and operational versatility. Features such as fork lift mode, side grappling of payloads, digging and positioning of lunar regolith, and a variety of special end effectors are described. LSMS operational viability depends on being able to reposition its base from an initial position on the lander to a mobility chassis or fixed locations around the lunar outpost. Preliminary concepts are presented for the second generation LSMS design, which will perform this self-offload capability. Incorporating design improvements, the second generation will have longer reach and three times the payload capability, yet it will have approximately equivalent mass to the first generation. Lastly, this paper covers improvements being made to the control system of the LSMS test-bed, which is currently operated using joint velocity control with visual cues. These improvements include joint angle sensors, inverse kinematics, and automated controls.
\end{abstract}

\section{Nomenclature}

ETDP $=$ Exploration Technology Development Program

HRS = Human Robotics Systems (Project)

LSMS = Lunar Surface Manipulation System

$M C C \quad=$ Multi-Center Cockpit

\footnotetext{
${ }^{1}$ Senior Research Engineer, Structural Concepts and Mechanics Branch, MS-190, Associate Fellow, AIAA.

${ }^{2}$ Research Engineer, Structural Concepts and Mechanics Branch, MS-190, Member, AIAA.

${ }^{3}$ Senior Research Engineer, Structural Concepts and Mechanics Branch, MS-190, Member, AIAA.

${ }^{4}$ Research Engineer, Vehicle Analysis Branch, MS-451, Senior Member, AIAA.

${ }^{5}$ Senior Designer.

${ }^{6}$ Senior Research Fellow, Fellow, AIAA. 


$$
\begin{array}{ll}
r & =\text { radius of contact surface for joint angle sensors } \\
R_{i} & =\text { initial radius of contact surface for joint angle sensors } \\
R_{o} & =\text { final radius of contact surface for joint angle sensors } \\
\theta & =\text { joint angle }
\end{array}
$$

\section{Introduction}

Devices for lifting, translating and precisely placing payloads are critical for efficient Earth-based construction operations. Recent and past studies have demonstrated that devices with similar functionality will be needed to support lunar outpost operations ${ }^{1,2}$. Lunar payloads include: a) prepackaged hardware and supplies that must be unloaded from landers and then accurately positioned at their operational site, b) sensor packages used for periodic inspection of landers, habitat surfaces, etc., and c) local materials such as regolith that require excavation and grading $^{3}$. Although several designs have been developed for Earth based applications, these devices lack unique design characteristics necessary for transport to and use on the harsh lunar surface ${ }^{4}$. These design characteristics include: a) lightweight components, b) compact packaging for launch, c) automated deployment, d) simple in-field reconfiguration and repair, and e) support for tele-operated or automated operations. Also, because the cost to transport mass to the lunar surface is very high, the number of devices that can be dedicated to surface operations will be limited. Thus, in contrast to Earth-based construction, where many single-purpose devices dominate a construction site, a lunar outpost will require a limited number of versatile devices which will provide ongoing operational benefit from initial construction through the life of the mission.

The first generation test-bed of a new high performance device, the Lunar Surface Manipulation System (LSMS) has been designed, built and tested ${ }^{5,6}$. Initial operational capabilities of the LSMS were successfully demonstrated using tele-operated control during field tests at Moses Lake, Washington. During these field tests, large and small payloads were routinely removed from and loaded onto an elevated platform, typically in under 5 minutes per payload (see Figure 1). Each sequence involved engaging a hook on the payload, lifting the payload and then positioning it either on the surface (unloading) or elevated platform (loading) then disengaging the hook. The LSMS has many unique features resulting in a mass efficient device for performing payload handling operations on the lunar surface. The mass of a typical LSMS that incorporates advanced structural features is estimated to be approximately $3 \%$ of the mass of the heaviest payload lifted at the tip, or $1.8 \%$ of the mass of the heaviest mass lifted at the elbow (mid-span of the boom) ${ }^{6}$. A unique feature of the design are spreaders that engage to act like spokes of a wheel to maintain mechanical advantage of the tension actuators about the joints as the joints rotate. These same spreaders

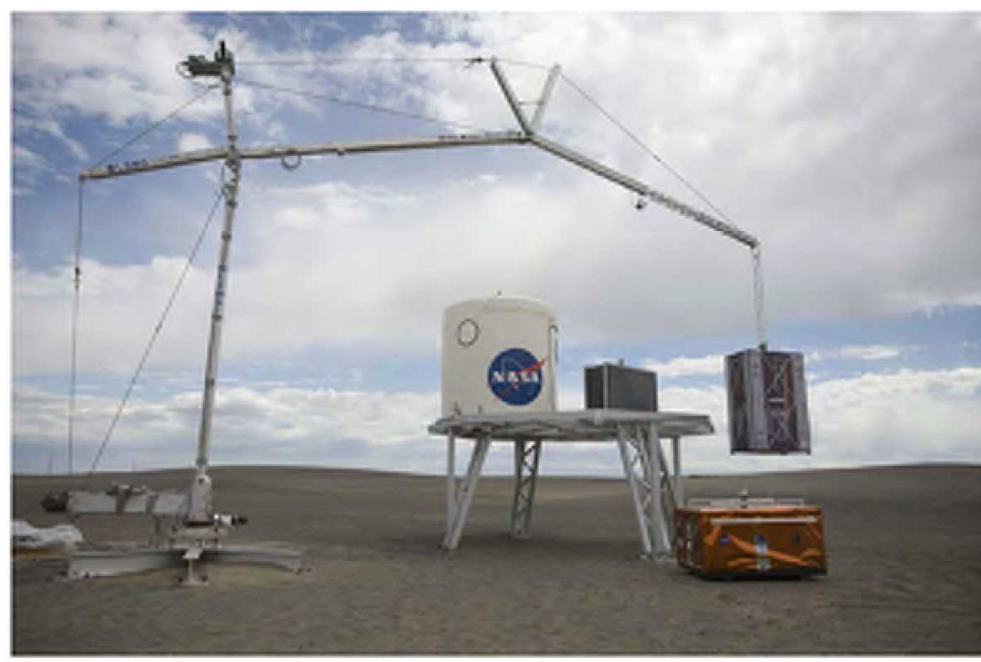

Figure 1. Payload handling operations performed at Moses Lake field test. automatically disengage, allowing the tension members to lift off for improved joint range of motion, resulting in a large operational workspace. This also enables unique operational configurations such as a fork-lift mode, allowing the LSMS to reach under landers or shelters. Conceptually, the LSMS can grapple a fixture at its wrist joint, release its base, and relocate the base enabling the LSMS to walk off the lander or move from a mobility vehicle to a fixed location.

Current LSMS development efforts are focused on three primary areas. The first is to expand the operational envelope and demonstrate increased operational versatility of the manipulator by making use of the first generation LSMS currently located in the Structures Laboratory at the Langley Research Center. The second area of focus is designing a second generation LSMS. The operational viability of the LSMS is strongly dependent on being able to reposition its base from its initial position on the lander onto mobility chassis as well as fixed locations around the lunar outpost. The primary goal of the second generation design is to incorporate this self-offload capability and 
complete the hardware design of all necessary supporting components. Currently, the LSMS is operated using joint velocity control with visual cues. The third and final area of focus will be to develop automation and remote control capability into the LSMS, with this work being accomplished using the first generation hardware. The objective of this paper is to describe and summarize the results of the development efforts in these three areas.

\section{Expanded LSMS Versatility}

Due to the large investment required to develop and test a device for lunar operations, it is critical that the device be versatile and able to accomplish a variety of tasks. Some of the operations that will be necessary to support a permanent lunar outpost include; off-loading a variety of payloads (many different sizes, shapes and masses) from landers, precisely manipulating and positioning surface systems (for assembly, construction and mating), supporting site preparation and regolith handling operations (scooping, digging, placing), supporting inspection and repair operations (positioning inspection and repair tools), and personnel positioning and transport (bucket truck operations, elevator). The operational versatility of the LSMS arises from its modular design and its capability to use a variety of different special purpose tools that can accomplish all of the operations previously cited. Conceptually, the LSMS will incorporate an automated quick-change interface at its wrist that provides a mechanical, electrical and data interface for all tools and end-effectors. The LSMS provides both a stable platform for, and precise positioning of a tool within the tool's workspace. Similar to industrial robots, the quick-change interface would provide automated engagement and release of tools, with all of the tools located within easy reach of the LSMS wrist. The current first generation LSMS incorporates a V-Groove dovetail mechanical interface (Figure 9 in Reference 5) that provides a structural connection to tools, with change-outs done manually ${ }^{5}$. An automated interface is currently in the planning stages and will be developed for the second generation device.

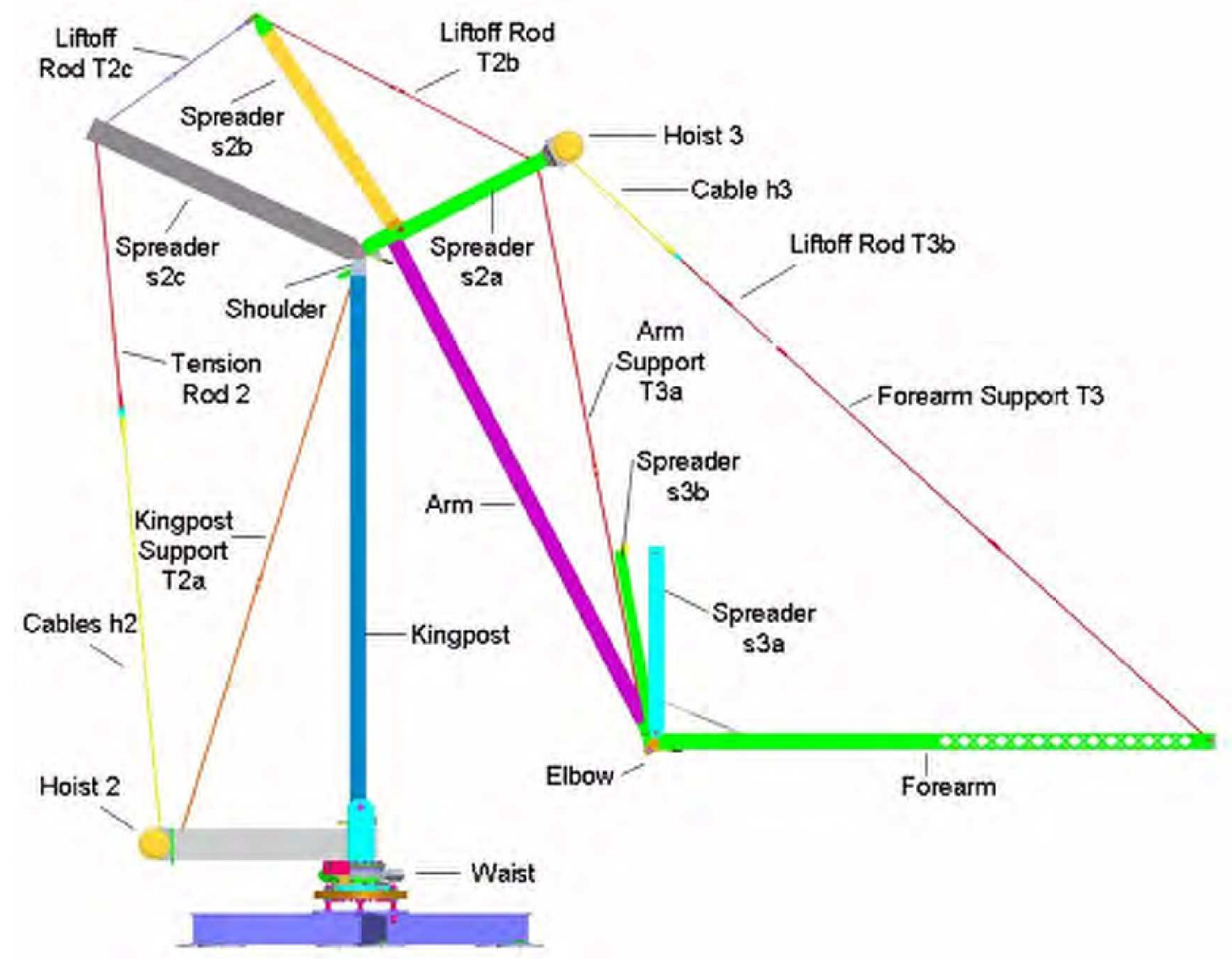

Figure 2. LSMS nomenclature.

Payload handling tests of a first generation LSMS, as depicted in Figure 2, were conducted during the Exploration Technology Development Program's Human Robotics Systems Project field test, held in June 2008 at Moses Lake, Washington ${ }^{5}$. These tests demonstrated conventional (crane type) payload handling configurations of 
the LSMS, where the arm down angle (with respect to the ground plane) was limited to approximately 45 degrees, and the forearm (relative to the arm) rotation angle could vary between -90 and +45 degrees. A simple passive lifting link, with a pin at the free end was used to engage hooks attached to the top surface of several representative

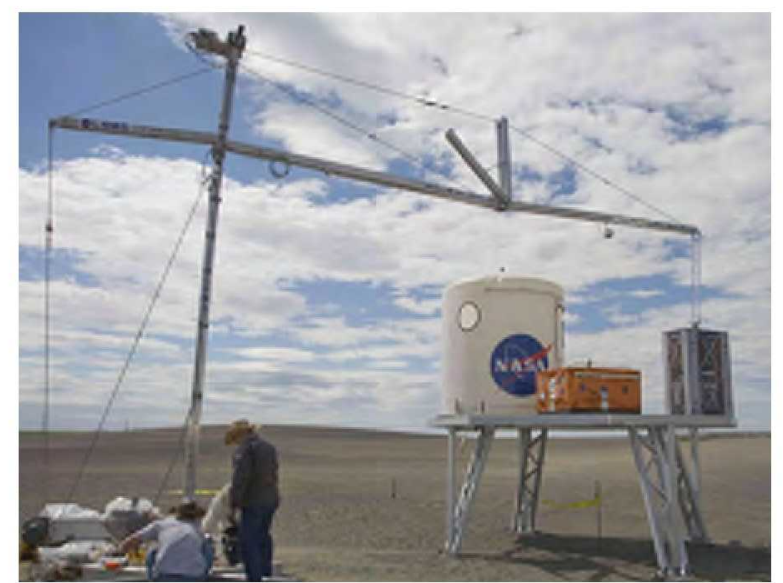

a) Conventional horizontal boom configuration.

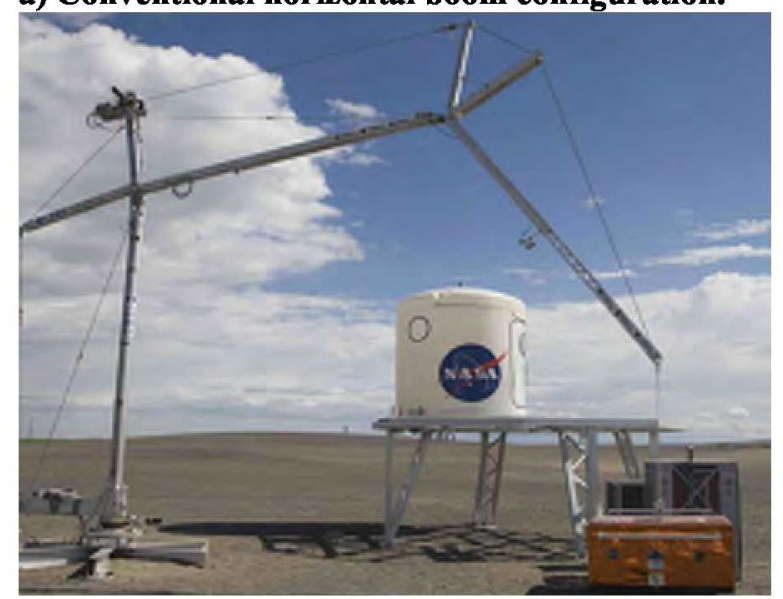

b) Manipulator mode.

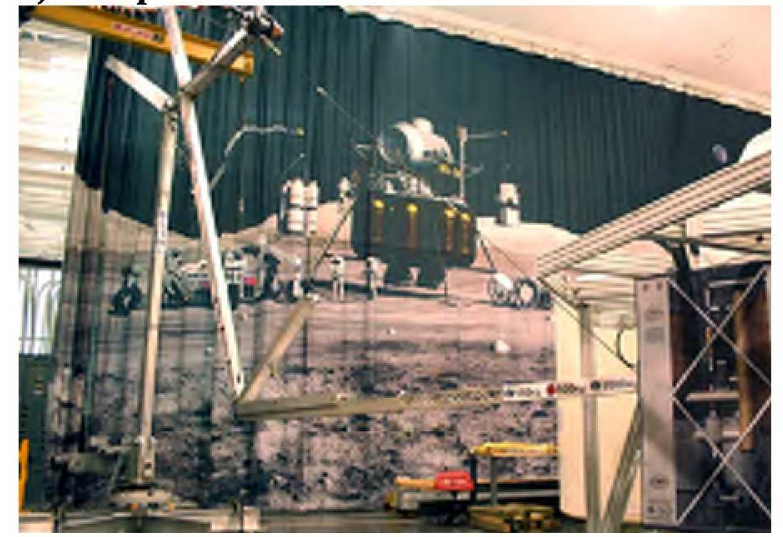

c) Fork-lift mode, reaching under lander mockup.

Figure 3. LSMS configurations.

payloads. In an operational mode very similar to conventional cranes, all of the payloads were grappled at the top hook and lifted vertically while suspended from the lifting link. Although the lifting configuration was fairly conventional, many innovations were demonstrated, including; manipulating payloads within an operational envelope using shoulder and elbow rotations, attaching lifting links and lifting payloads from both the elbow and wrist, operating off of a variety of fixed (ground and lander mockup) and mobile (such as ATHLETE ${ }^{7}$ ) bases, and remote controlled payload transfer to a mobile chassis.

Expanding the LSMS versatility to allow manipulation, positioning and regolith handling operations, required expanding the shoulder joint range of motion. In particular, increasing the angle to which the shoulder joint could be rotated down (from the horizontal) was required to allow the LSMS to reconfigure to the fork lift geometry. In Figure 3, three representative LSMS configurations are shown. In Figure 3a, the arm and forearm are both horizontal to the ground and the LSMS looks like a conventional crane. In this configuration the LSMS achieves its maximum horizontal reach. In Figure 3b, the arm is rotated up and the forearm is rotated down, achieving a configuration similar to a robotic manipulator. In Figure $3 \mathrm{c}$, the arm is rotated down to its maximum angle and the forearm is rotated up so that it is horizontal to the ground plane, resulting in the Fork Lift configuration. In order to maintain the mechanical advantage of tension member cable $\mathrm{h} 2$ with respect to the king post when the arm is rotated to $\mathbf{- 7 0}$ degrees, a third spreader, $\mathrm{s} 2 \mathrm{c}$, was added to the shoulder joint (see Figure 2). All of the spreaders have been set such that the LSMS can execute its full range of motion while automatically engaging and disengaging the spreaders as necessary, as shown in Figure 3. In all configurations, the compression and tension members always form a series of triangles that maintains the structural integrity of the device.

FEM analysis, using the ABAQUS software, was used to determine the effect of the forklift configuration on the global buckling and loading of the LSMS. The analysis model has been previously described and shown to correlate with load tests performed on the prototype LSMS $^{5}$. The model uses highly efficient shear flexible beam elements and includes all offsets at the joint locations. The pinned joints are modeled as kinematic coupling constraints with one degree of freedom in rotation. Custom scripts allow the model to be quickly and easily reconfigured into any operational geometry, including configurations where the cables have disengaged the spreaders, such as the forklift mode (Figure 4). Meshing, boundary conditions and load definition are applied automatically after regeneration of the model. Non- 
linear analysis is used to account for the geometric stiffness of the cables under gravitational and applied loads and to propagate the resultant stress state into the buckling step.
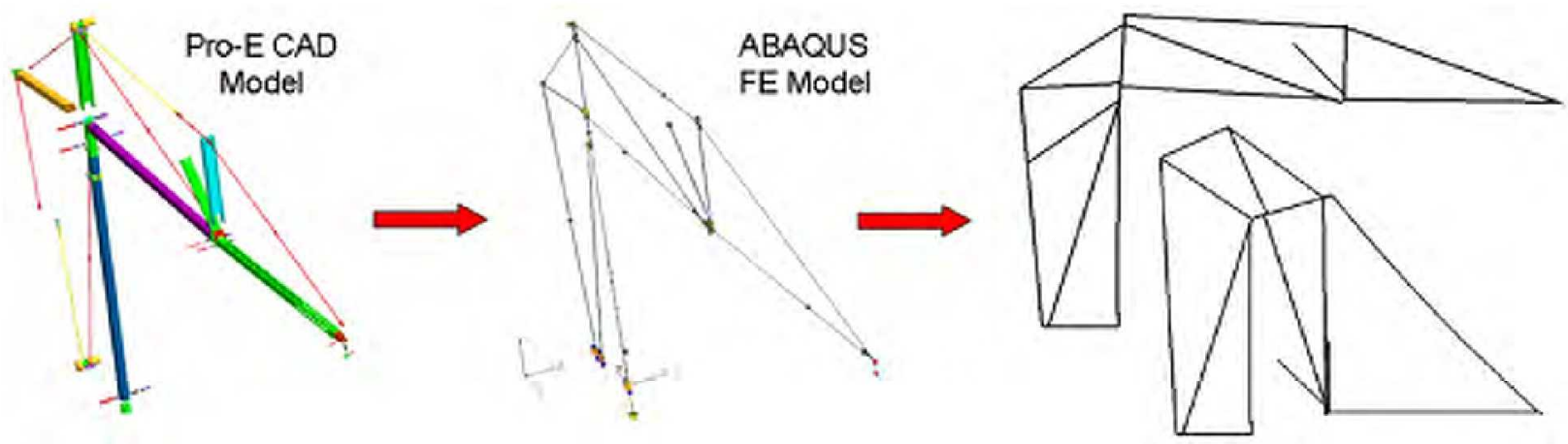

Figure 4. LSMS finite element structural analysis model.

The forklift configuration requires the arm to be rotated downward by 70 degrees, while the forearm is rotated upward by 70 degrees, leaving the forearm parallel with the ground. As discussed previously, this maneuver requires a tertiary spreader, $s 2 c$, to be integrated at the shoulder joint below the $\mathrm{s} 2 \mathrm{~b}$ spreader. This additional member was added to the FE model and linear buckling and nonlinear Riks analyses were performed for both the baseline (both arm and forearms horizontal) configuration and the forklift mode to determine the global buckling loads under the maximum operating design tip load of $330 \mathrm{lbs}$. The $1^{\text {st }}$ buckling mode occurs at approximately 3.9 times the applied $330 \mathrm{lbs}$ operating load for the baseline configuration, and at 6.5 times the operating design load for the forklift mode. This increase in buckling load is primarily due to the significant reduction of the moment arm between the wrist and the kingpost (the king post bending stiffness is the primary driver in the global buckling mode) as well as the lowering of the LSMS center-of-gravity (c.g). Similarly, the buckling load tends to increase for the majority of configurations where the wrist is at less than the full reach of the LSMS. The major exception to this are configurations having large up-angles of the entire arm and fore-arm links, which raises the c.g and reduces the buckling factor of the system by up to $15 \%$ from the baseline. A static analysis was also performed at the design load to determine the redistribution of loads while in the forklift mode. The loading in all members, except the tertiary s2c spreader is reduced in the forklift configuration as shown in Figure 5, as might be expected given the results of the buckling analysis. It should be noted that the tertiary spreader is disengaged in the baseline mode, and only picks up load as the arm is rotated down into forklift mode. The secondary (s2b) spreader on the forearm is also not engaged in either of these modes, and therefore maintains zero load.

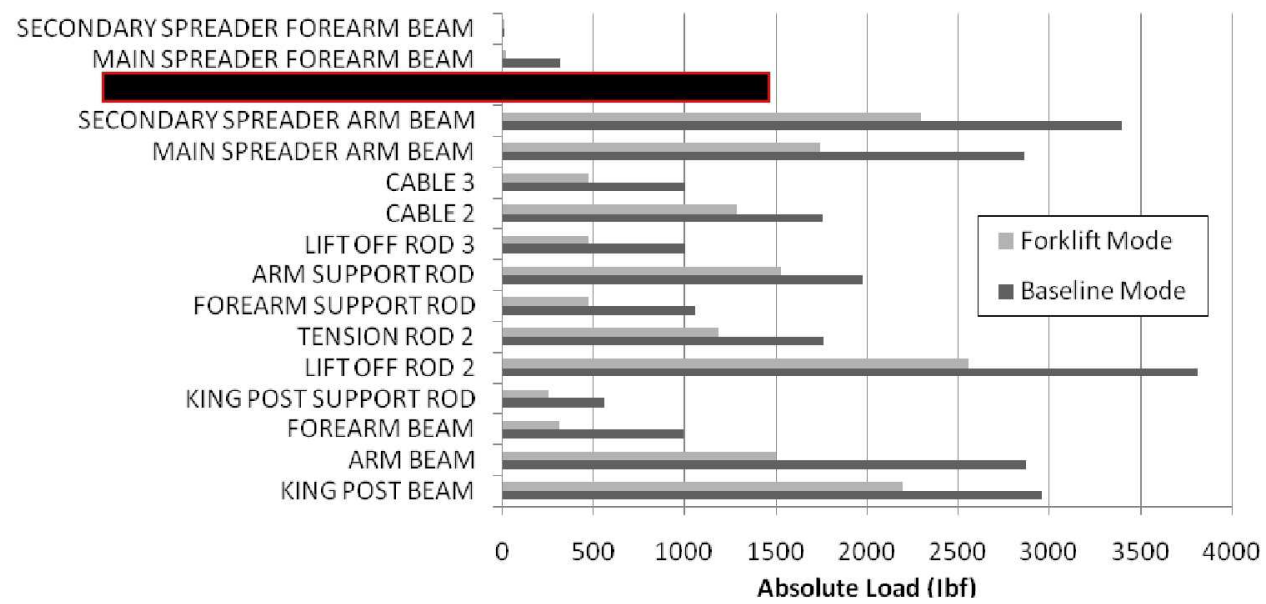

Figure 5. LSMS member loads for conventional and fork-lift configurations.

A variety of end effectors are being developed that will allow the LSMS to demonstrate operational versatility. For general purpose handling and other operations, a capability to grapple payloads on the side, or reach under objects would be very useful and substantially increase the versatility of the LSMS. As a result, a design effort has been initiated to develop a gripper end-effector that can be attached to the LSMS wrist. This gripper/bumper system, shown in Figure 6, allows the LSMS to grapple payloads from the side. Currently, the bumper system has been designed and fabricated, all of the gripper parts have been designed, and fabrication of gripper parts has been 
initiated. In order to demonstrate side grapple of a payload and removal from underneath the upper deck of a lander, the same VGroove dove tail system used to attach the fixed-length lifting link to the wrist was reproduced and mounted to the side of one of the payload mockups. This attachment mechanism, coupled with operating in the forklift mode was used to demonstrate the LSMS capability to remove payloads from beneath the deck of a lander, as shown in Figure 7. In order to mount the payload, two support ledges (at the rear) and a single support hook (in the front) were mounted to the bottom of the lander deck. Two support bars were mounted to the top of the payload and engaged the ledges/hook as shown in Figure 7a. An operational procedure was executed to remove the payload, which included the steps: 1) the LSMS wrist is maneuvered below the V-Groove fixture on the payload (Figure 7a); 2) the wrist is elevated so that it engages and locks to the fixture on the payload (Figure 7b); 3) using simultaneous shoulder and elbow rotation, the payload is lifted vertically so that the top bars clear the top of the hooks and the payload is extracted horizontally (Figure 7c); and finally, 4) the payload is extracted from under the lander, rotated out from underneath the lander deck, and set down on the surface (Figure 7d). Note that the distance between the bottom of the lander deck and the top of the support bars on the payload is approximately one inch, but

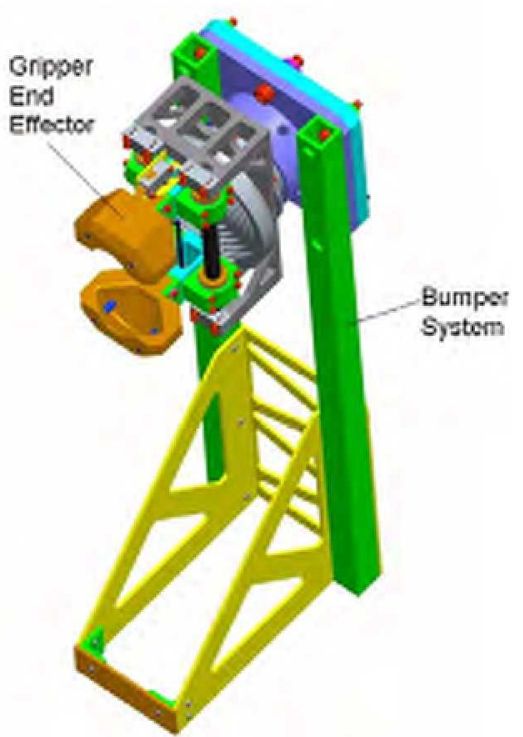

Figure 6. Gripper end effector with bumper support system. because of the precise positioning capability of the LSMS, this clearance proved to be more than adequate. The dexterity of the LSMS together with its precise positioning capability also allowed the process to be reversed; the payload was lifted from the surface, positioned under the lander deck and rehung on the support ledges/hook system. Another application of using a gripper end effector is to scavenge liquid oxygen tanks from under a lander payload deck, as shown in Figure 8, so that they might be reused in conjunction with a lunar surface in-situ oxygen production plant.

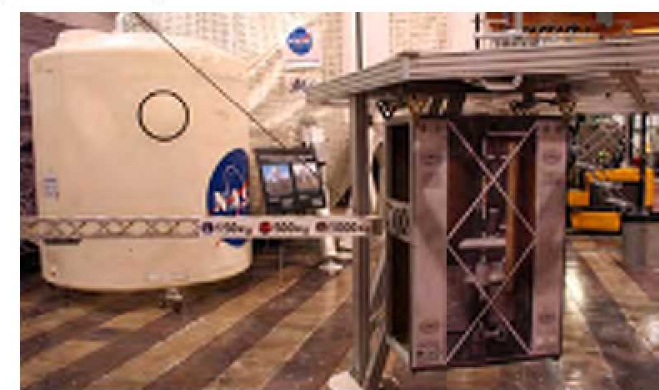

a) Wrist approaching grapple fixture.

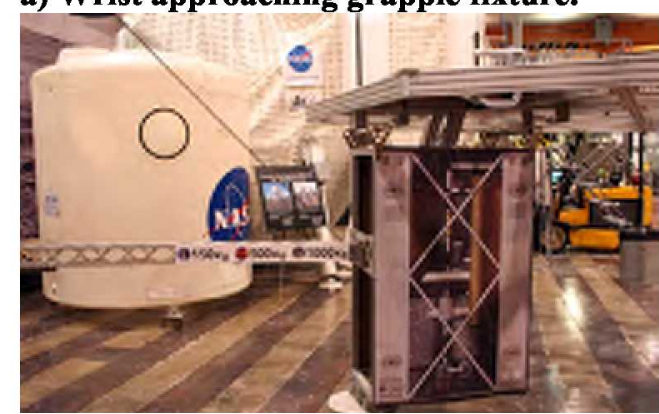

c) LSMS has lifted payload off support mounts.

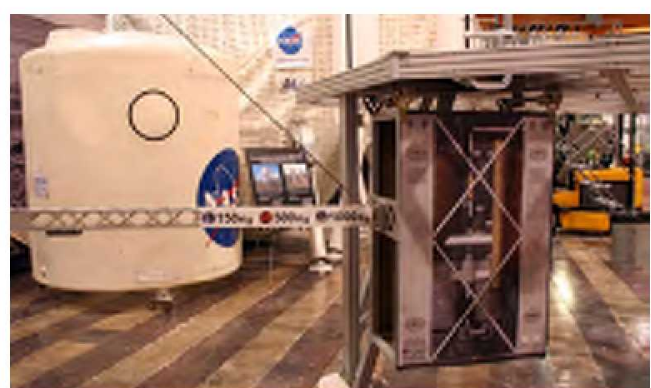

b) Wrist grapples ISRU payload.

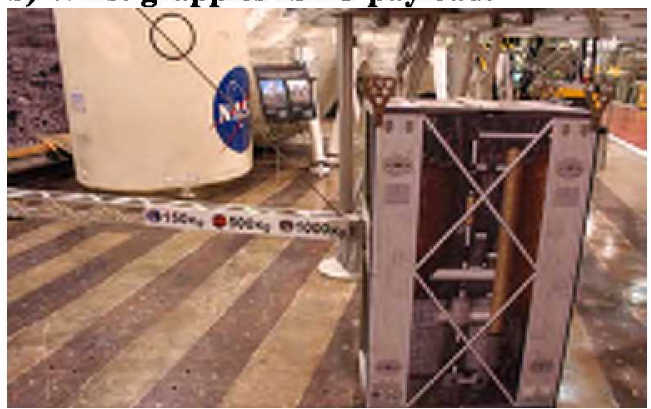

d) Payload is set on surface.

Figure 7. LSMS removes payload from underneath the lander deck. 
The lunar regolith is an example of a local resource that can serve many purposes, especially as augmented radiation shielding. Protecting humans from the damaging effects caused by long term exposure to galactic cosmic rays (GCR) is a concern for permanently occupied Lunar or Mars outposts. One way to mitigate the exposure, that has the benefit of not requiring mass to be transported from the Earth, is to use local regolith as a shielding material. For example, shelters or scaffolding could be built over the habitation modules, and a sufficient depth of regolith piled on top of the shelters to block the

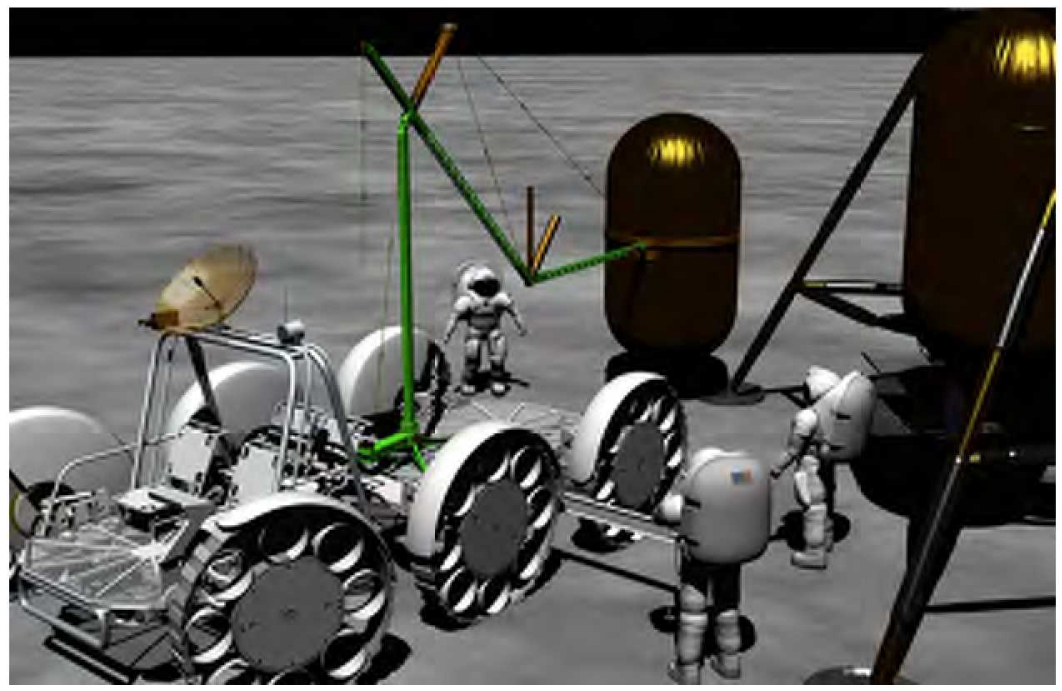

Figure 8. LSMS in forklift mode scavenging fuel tank from lunar lander.

GCR. In another example, lunar outpost concepts have been studied where the outpost power is provided by nuclear (as opposed to solar photovoltaic) energy. In one study, the nuclear reactor is located in a cavity in the lander deck and remains in that cavity for the duration of it's operational life. In order to allow the reactor to be located near the outpost (to minimize the mass of power cabling) lunar regolith is used to fill the cavity around the reactor and attenuate the radiation produced. For both of these examples, a Scoop End Effector on the LSMS could be used to dig regolith and dump or place it where needed.

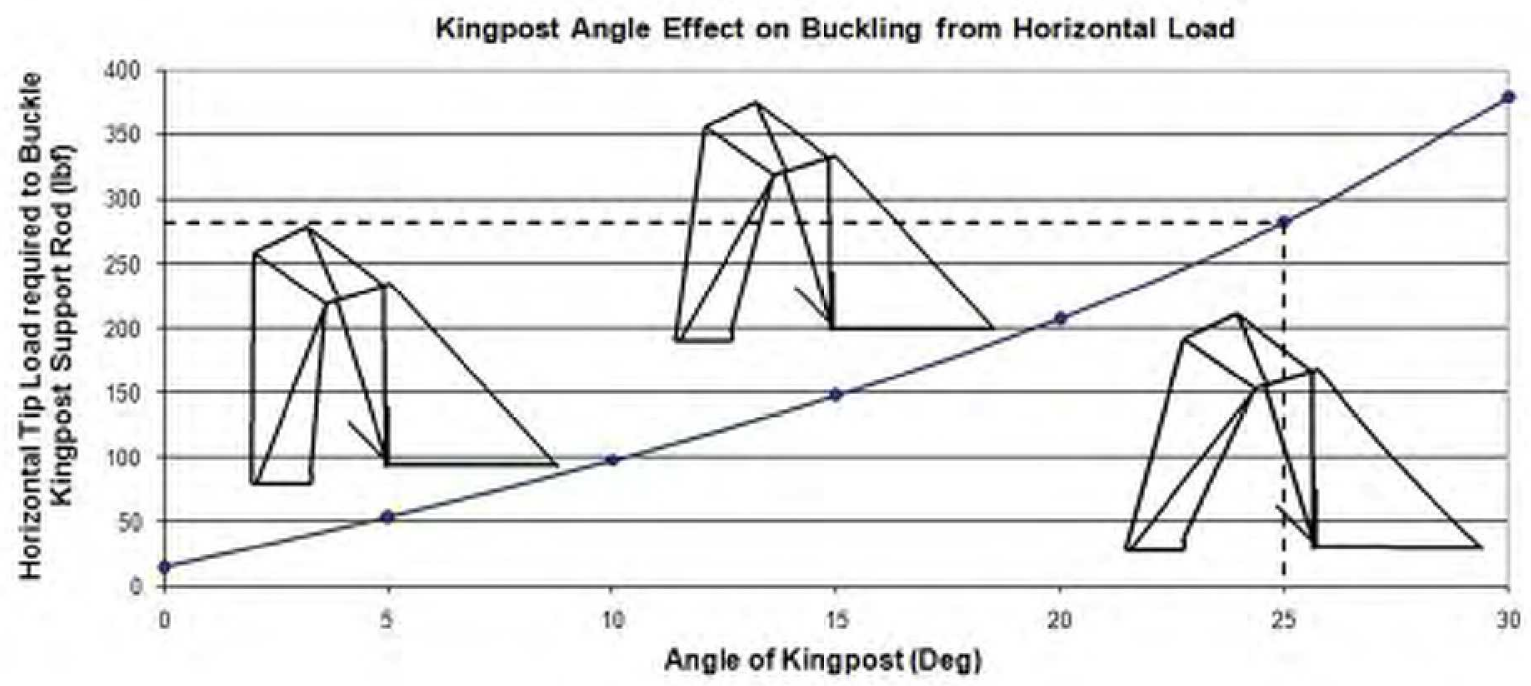

Figure 9. Effect of king post forward lean on horizontal digging force.

In another demonstration of LSMS versatility, a regolith scoop end effector has been designed, fabricated and used to demonstrate regolith handling operations. In order to dig or scoop regolith from the surface, the LSMS must be in the forklift mode (with the forearm parallel to and very close to the ground), with the shoulder and elbow joints operating simultaneously to push the scoop forward. With the current layout of tension rods/cables in the first generation LSMS, as the scoop is pushed forward, the reaction forces result in compression forces in some of the tension rods and cables. When this force overcomes the tension induced due to the mass of the LSMS links and the scoop end effector, it would cause the king post to rock backwards, with only a safety stop preventing the king post from completely falling backwards. Leaning the King Post forward (from the vertical) increases the preload in the critical King Post support rod, which reacts most of the compressive forces induced by digging. The original fixedlength support rod (labeled "king post support, T2a," in Figure 2) has been modified to include an in-line come- 
along that allows the king post to be easily rotated between a vertical orientation, used for conventional payload handling and forklift operations, and the forward angle used for scooping.

FEM analysis was performed to determine a suitable King Post forward angle for digging operations, which directly affects the amount of pushing force available. To determine an appropriate kingpost angle, static analyses were run at varying lean angles and the load required to buckle the kingpost support rod was determined (Figure 9). An angle of 25 degrees, which provides a limiting pushing force of $282 \mathrm{lbf}$, was found during Lab testing in the laboratory to be sufficient for scooping a full bucket $(150 \sim 160 \mathrm{lbs})$ of sand with no rock-back of the kingpost.

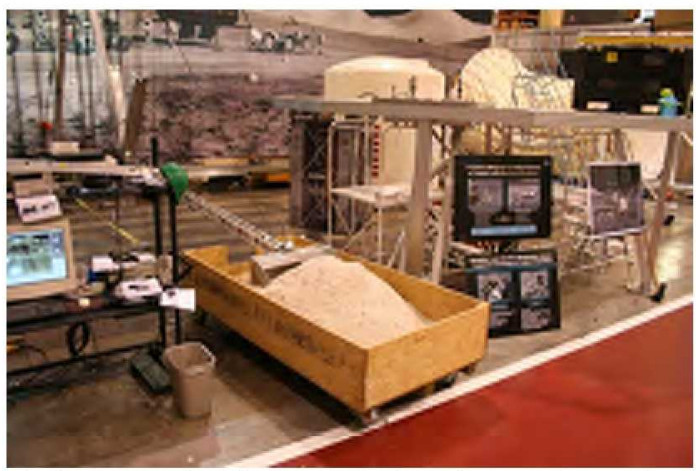

a) Scoop end-effector moving through sand.

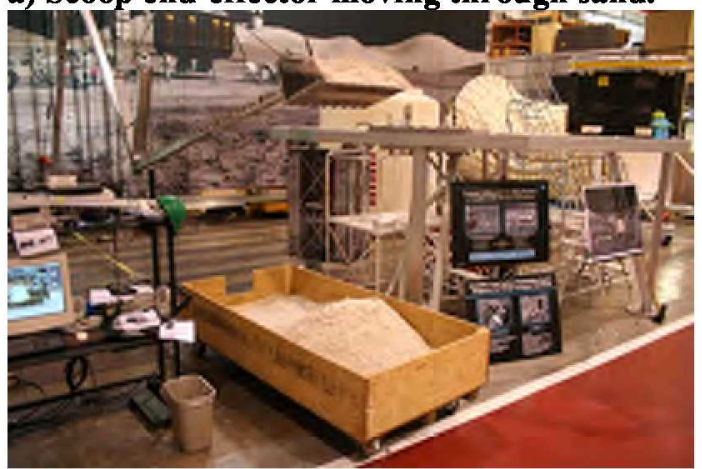

b) Raising scooped sand above lander deck.

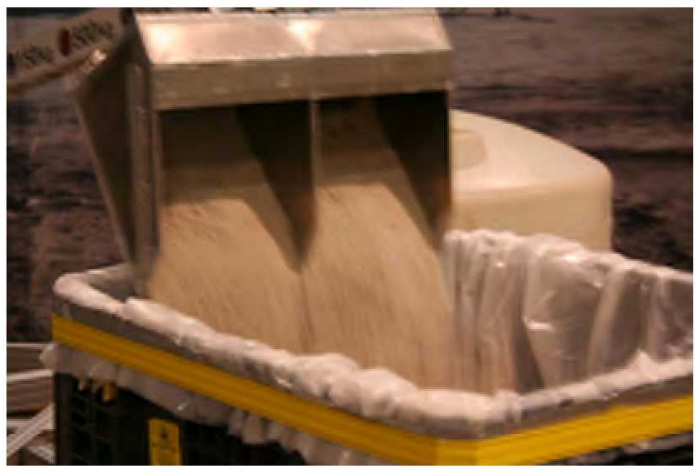

c) Dumping sand into container on top of lander deck.

Figure 10. Scooping and dumping sand to simulate regolith shielding for nuclear reactor. dump the load into the crate (Figure 10c). The scoop is then
pulled backwards against the top lip of the box, rotating it back up to horizontal and reengaging the latch. This
process was repeated several times and the time to complete one cycle of acquiring a load, dumping it, relatching the process was repeated several times and the time to complete one cycle of acquiring a load, dumping it, relatching the bucket and getting in position to acquire the next load varied between 9 and 10 minutes.

Further analyses were performed to check the global buckling and local member loads for this operational mode. The global buckling factor at 25 degrees tilt is reduced by $15 \%$ to 5.6 , which is still $44 \%$ higher than the baseline configuration. The preload in the kingpost support rod, due to just the mass of the LSMS in earth gravity, is $37 \mathrm{lbs}$ in the baseline configuration but increases to $738 \mathrm{lbs}$ when the king post is leaned forward in digging mode. If the design tip load is added, the kingpost support rod sees a $244 \mathrm{lbs}$ baseline load and $2131 \mathrm{lbs}$ in the digging configuration. This is less than $20 \%$ of the ultimate strength of the rod used and well within design limits. Knowing the load required to put the support rod into compression from analysis, and observing the onset of "rock back" provides a very simple and benign indicator in the lab of the loads being induced due to digging operations.

The scoop end effector was designed by the LSMS team with all parts fabricated in the LaRC shops. It is made out of aluminum and the bucket portion, which is welded from plate, has dimensions of 30 inches wide, by 20 inches deep, and 12 inches tall, and is designed for a load of $150 \mathrm{lbf}$ of material. A separate hinge and latching mechanism was designed, fabricated, assembled and attached to complete the bucket. The entire scoop end effector weighs $60 \mathrm{lbf}$. This latching/dumping mechanism also incorporates a V-Groove dove tail plate for attaching to the LSMS wrist. Sand is used to simulate lunar regolith and is contained in a large box constructed for use in the laboratory environment. In initial tests, the scoop on average excavated between $150-160 \mathrm{lbf}$ of sand. Subsequent operational testing was conducted to simulate the operation where lunar regolith is used to shield a nuclear reactor on the lunar lander. In the laboratory setup, the LSMS and sandbox are on the ground and a crate (representing the cavity around the nuclear reactor) is placed on top of the lander mockup. The LSMS starts with the king post leaning forward, the forearm horizontal and close to the floor and the scoop ready to engage the sand pile in the box (Figure 10a). By simultaneously rotating the shoulder and elbow joints, the scoop is driven forward into the sand pile until a significant amount of sand is retained. The arm and forearm are then elevated above the height of the box on the lander (Figure 10b) and rotated (using the waist joint) until the scoop is positioned over the crate. A solenoid is actuated, which releases the bucket locking mechanism, allowing it to swing down and dump the load into the crate (Figure 10c). The scoop is then 8 American Institute of Aeronautics and Astronautics 


\section{Second Generation LSMS Design}

The LSMS will initially arrive at the lunar surface attached to the top of a lander deck, and from there, unload payloads and equipment to the lunar surface. It would not be either mass or cost effective if each lander had to include a LSMS for unloading operations. In addition, the capability to move and manipulate payloads and regolith, and perform inspection and repair operations will be required at many locations on the lunar surface for the lifetime of the outpost. Thus, the operational viability of the LSMS strongly depends on it being a repositionable and mobile system with the ability to relocate its base from its initial position on the lander onto a mobility chassis or fixed locations around the lunar outpost. This would allow the LSMS to unload subsequent cargo landers as they arrived, for example. The primary goal of the second generation design effort is to incorporate this self-offload capability and complete the hardware design of all necessary supporting components. The team has also established a performance goal; that the second generation LSMS mass be no greater than that of the first generation LSMS.

\section{A. New Operational Mode and Modified Requirements}

A depiction of the LSMS off loading itself from a lander is shown in Figure 11. After the lander has been unloaded, the LSMS changes the end-effector at its wrist to a special-purpose grapple/support mechanism, and using that, reaches down and grapples a simple fixture on the lander deck (Figure 11Figure 11a). The base of the LSMS is then released from its fixture on the lander deck and elevated using the elbow and shoulder joints (Figure 11b). The special-purpose grapple/support mechanism uses its rotational degree of freedom to rotate the base of the LSMS out over the lunar surface, and the LSMS shoulder and elbow joints are used to lower the base onto the bed of a mobility chassis (Figure 11c) or a fixed base. The mobility chassis would have a fixture identical to that on the lander that the LSMS base would automatically acquire and connect to. At this point, the LSMS becomes a mobile asset at the outpost.

The first generation LSMS was sized to be a full-scale manipulator, with the ability to unload a lander while the LSMS was positioned on either the surface or a mobility chassis. However, it is a relatively light-duty device, with a lunar payload capability at the wrist of $1000 \mathrm{~kg}$ (2000 kg at the elbow). As architecture and lander studies

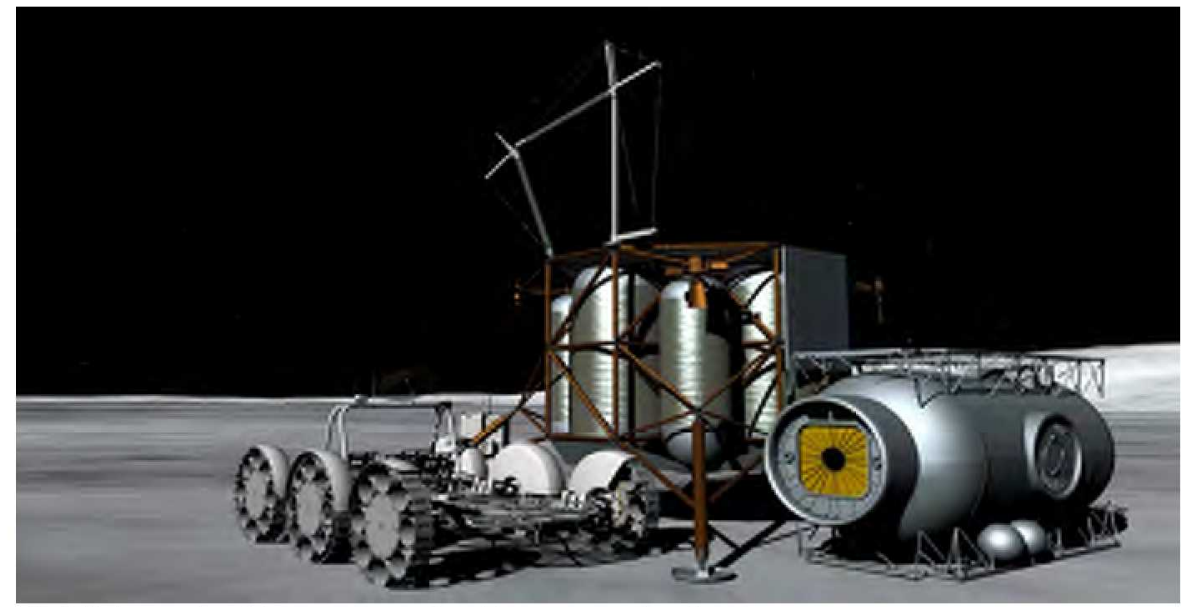

a) Wrist end-effector grapples fixture on lander.

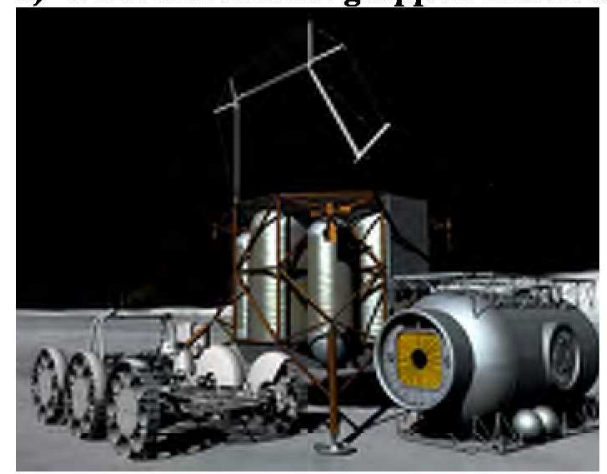

b) Base is Released. Figure 11. LSMS maneuver for self-offloading and repositioning.

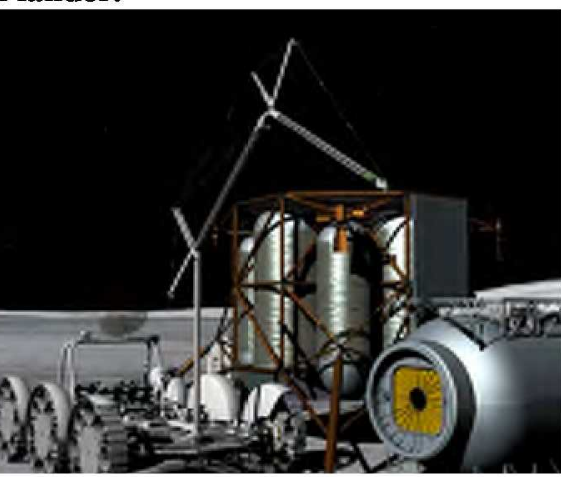

c) Base is lowered onto mobility chassis. progressed, the height of the cargo lander deck increased slightly, and the operations of the LSMS were expanded to include all payloads being brought to the lunar surface. Table 1 shows the various LSMS concepts that have been developed to support all of the current architecture studies. As a result, the performance of the second generation LSMS (compared to that of the first generation device) will be upgraded. Its horizontal reach will be increased from 7.5 to 8.5 meters, so that given the current definition of the Altair Lander, the second generation LSMS will be a full scale device capable of unloading cargo from the lander deck

American Institute of Aeronautics and Astronautics 
(approximately 6.5 meters from the lunar surface) while the LSMS is on the lunar surface beside the lander. The lunar payload capability is being increased to $3000 \mathrm{~kg}$ at the wrist, and $5226 \mathrm{~kg}$ at the elbow, allowing the second generation LSMS to lift most of the potential payloads coming to the lunar surface.

Table 1. Sizing summary of medium- and heavy-lift versions of the LSMS

\begin{tabular}{|c|ccccccc|}
\hline $\begin{array}{c}\text { Design } \\
\text { Identifier }\end{array}$ & $\begin{array}{c}\text { Height } \\
(\eta R[\mathbf{m}])\end{array}$ & $\begin{array}{c}\text { Reach } \\
(\mathbf{R}[\mathrm{m}])\end{array}$ & $\begin{array}{c}\text { Elbow Loc. } \\
(\beta R[\mathrm{~m}])\end{array}$ & $\begin{array}{c}\text { Lunar Wrist } \\
\text { Capacity([kg]) }\end{array}$ & $\begin{array}{c}\text { Lunar Elbow } \\
\text { Capacity([kg]) }\end{array}$ & $\begin{array}{c}\text { Device } \\
\text { Mass[kg] }\end{array}$ & $\begin{array}{c}\text { Construction } \\
\text { Type }\end{array}$ \\
\hline Generation I & 3.75 & 7.5 & 3.76 & 1,000 & 1,742 & 309 & Al Tube \\
\hline Generation II & 4.25 & 8.5 & 4.26 & 3,000 & 5,226 & 190 & Al Truss \\
\hline Moderate Lift & 3.75 & 7.5 & 3.76 & 4879 & $\mathbf{8 , 5 0 0}$ & 108 & Composite \\
\hline Heavy Lift & 4.17 & $\mathbf{8 . 3 4}$ & 4.18 & 6907 & 12,033 & 169 & Composite \\
\hline
\end{tabular}

\section{B. Design Modifications}

In order to accommodate the self-offload capability and the increased reach and payload requirements, several design modifications will be required for the second generation LSMS. The first is a slight change in the layout of the tension members. An analysis was performed with the First Generation LSMS configuration where the manipulator was modeled in the configuration show in Figure 11b, with the wrist grappling the lander fixture and the base released and slightly elevated. As the gravity load was applied, the tension member h3 shown in Figure 2 attempted to react a induced compressive load. In order for the LSMS to support itself in this reverse loading configuration, the $\mathrm{h} 3$ cable connection point to the s2a spreader was moved from the top to bottom of the spreader as shown in Figure 12. This configuration maintains the integrity of the tension-compression design for all operational scenarios. Because it only has to support it's own mass, the internal loads induced in the LSMS in the self offloading configuration are much smaller than those induced during regular payload handling operations, and do not impact sizing of the tension and compression members.

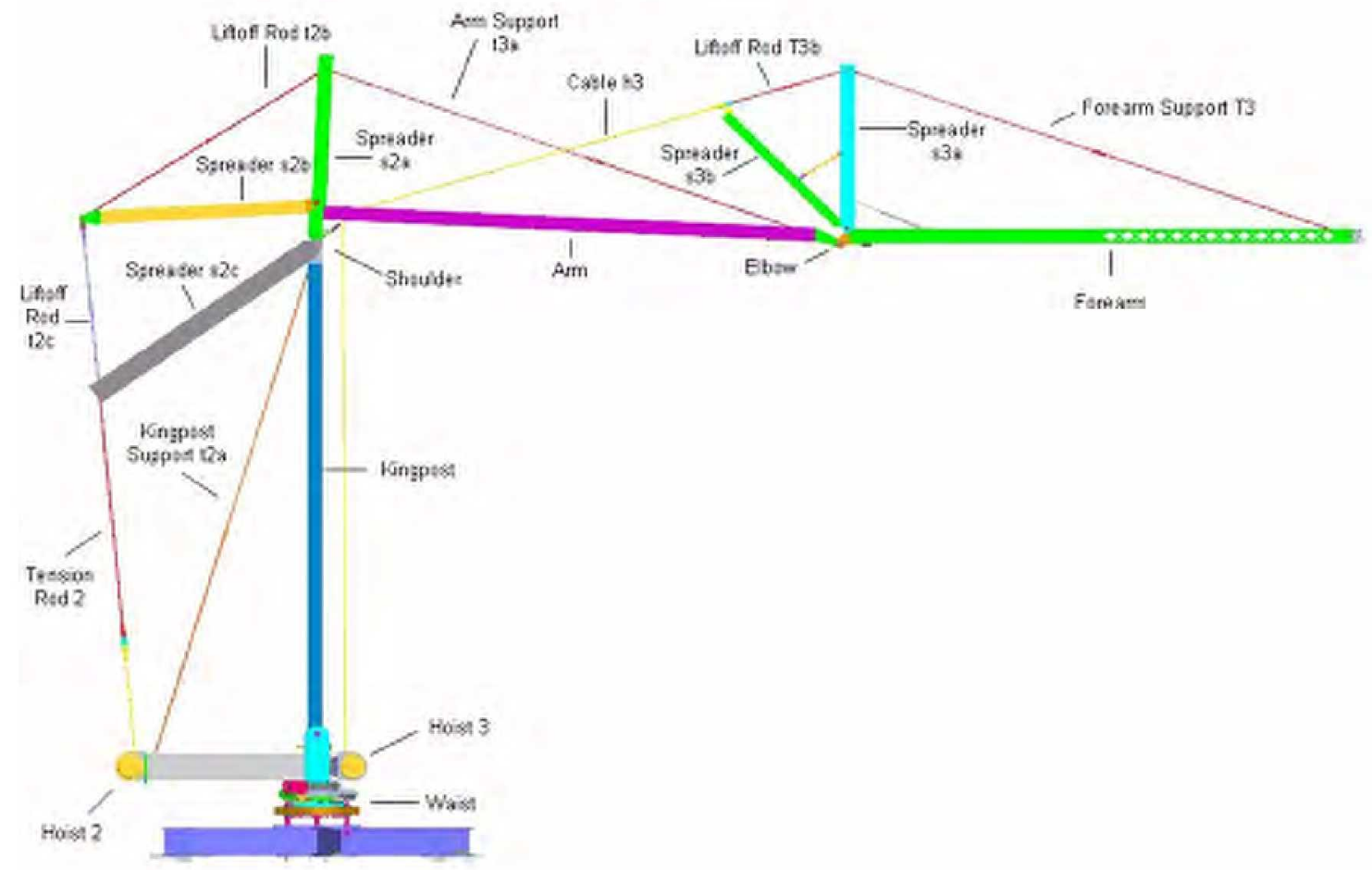

Figure 12. Second Generation LSMS Configuration. 
In the first generation LSMS, a heavy (85 lbf) off-theshelf turn-table bearing was used in the waist rotary joint. In the self-offloading configuration, the waist joint acts as a concentrated tip mass, and has a significant effect on the magnitude of the forces and moments which will be generated at the wrist and the associated special-purpose grapple/support mechanism. In order to minimize these forces and moments, a new, lightweight waist joint will be designed for the second generation LSMS. Initially, two different concepts were evaluated; one based on having a single bearing, and a second based on multiple bearings. In the end, the best features were taken from each concept and combined to give the two-bearing concept shown in Figure 13. Key features which should result in this being a lighter weight joint include: 1) the overall diameter is smaller; 2) the housing will be manufactured from aluminum (instead of steel); 3) the worm drive will be replaced with a cable drive (see Figure 13); 4) a large number of fasteners (and their associated weight) are eliminated; and, 5) a single nut is used to preload the bearing.

In reference 6, equations are given to calculate the sizing and mass for a LSMS with tubular members (as used in the first generation configuration) and for a LSMS with truss members. In addition, aluminum and polymeric composite material can be specified when calculating mass. When the same material is used for both, the results from reference 6 show that for a given reach and maximum payload capability, truss members only have approximately half the mass of tubular members. In order to meet the mass performance goal given in Table 1, as well as increase (by one meter) the reach and maximum load capability at the wrist (tripled) compared to the first generation device, truss members are being used in the second generation LSMS. As with the first generation LSMS, aluminum will be used for the links to minimize material and fabrication costs and the time to complete assembly. In the current concept, the members will begin as custom extrusions, they will be cut to length and a pattern of triangular cutouts will be machined on all four sides of the extrusion resulting in an integral truss member, as shown in Figure 14a. The extrusion cross-sectional dimensions are shown in Figure 14b.
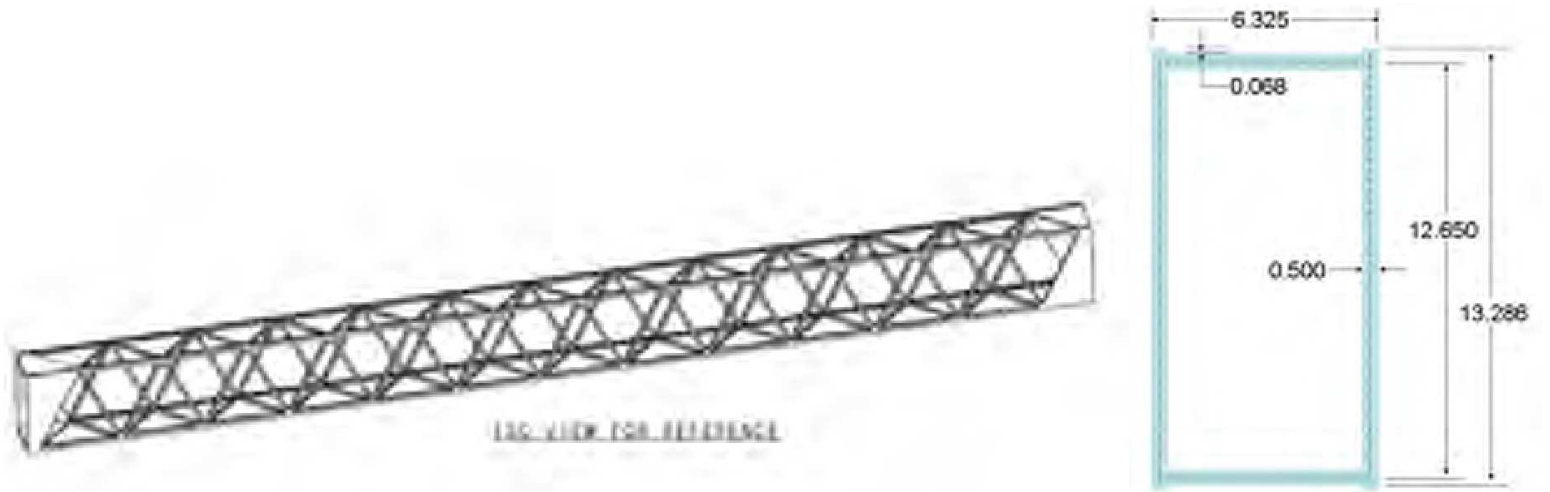

a) Machined truss geometry. Figure 14. Second generation LSMS truss geometry.

b) Extrusion cross-section dimensions.

At this time, preliminary sizing has been completed for the truss members. The applied compression load in the king post is calculated using the method in reference 6 and the king post sizing is used for all three primary compression members. Reference 6 was also used to determine the king post bending stiffness required to resist Euler column buckling due to a maximum tip load. An analytical procedure, developed to augment that described in reference 6 , discreetly models the longerons and diagonals in the truss, allowing their cross-sections to be sized for local Euler buckling. The applied compressive load is divided amongst all four truss longerons to determine their 
local buckling load. In order to size the diagonal truss members, a applied load that will induce torsion in the king post is required. Two cases were evaluated; the first is one where the king post is tilted laterally away from the vertical plane $(1,2$, and 3 degree tilts were evaluated) so that the vertical payload force acting at the wrist creates a moment that causes a torque in the king post. Since the LSMS is always set level before payload handling operations begin, this condition is unlikely to occur. The second case is based on operational experience; in previous field testing ${ }^{5}$ the LSMS experienced torsional loads due to wind-induced drag on the payloads suspended at the wrist. Applied torsional loads were calculated based on a payload with a surface area of 16 square feet and wind velocities up to a maximum of $45 \mathrm{mph}$. Since the torsional load is coupled with the global LSMS buckling mode, a factor of safety of 4.0 was used to establish a king post critical torque value. Limiting LSMS operations in the field to wind velocities below 32 miles per hour results in a critical design torque value of 15,400 in-lbf, which also corresponds to a tilt angle of 2.4 degrees with a $500 \mathrm{~kg}$ tip mass.

With the design and loads specified previously, a king post sizing study was performed where the main variable was the wall thickness (see Figure 14b) of the truss cross-section. The width of the cross-section was specified to be twice the depth, as shown in the figure. Based on this preliminary sizing, the selected truss cross section has a width of 6.32 inches, a height of 12.65 inches and a wall thickness of 0.5 inches. The resulting total truss mass is $256 \mathrm{lbf}$ $(117 \mathrm{~kg})$. Figure 15 shows the mass of aluminum tubular and truss cable boom (LSMS type) manipulators calculated using the methods in reference 6. For the integral truss boom being developed for the second generation LSMS, sized using more refined methods, the predicted second generation LSMS truss mass is seen to be slightly less than the original predicted value.

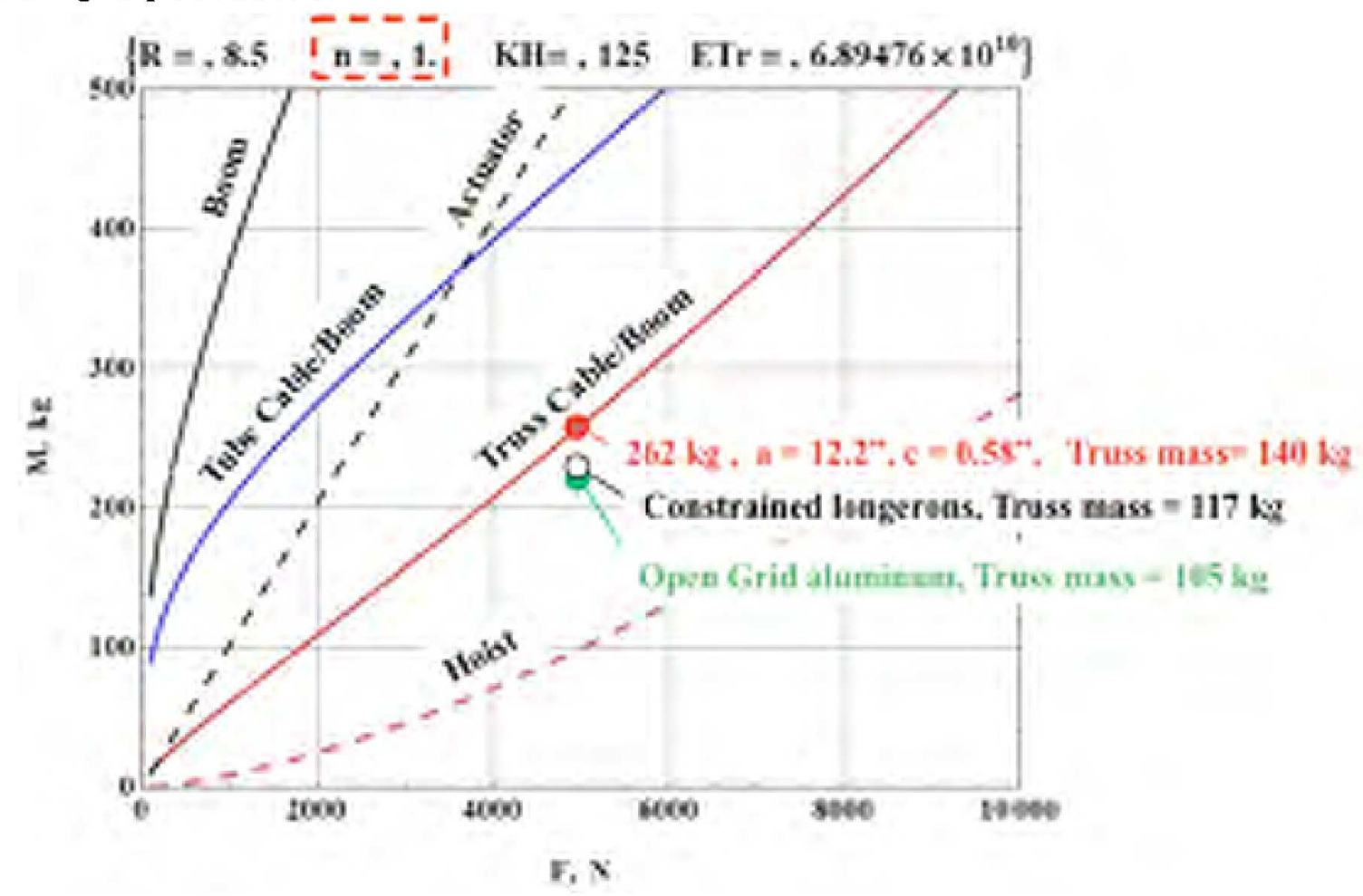

Figure 15. Second generation LSMS truss link mass estimates.

\section{Remote Control}

A major goal of the LSMS project for FY09 is to integrate the LSMS into the HRS remote control infrastructure, known as the Robot Application Programming Interface Delegate (RAPID) system, and develop the capability to operate the LSMS from a remote site. The goal of the multi-center RAPID project is to create a common operations system capable of monitoring and commanding all elements of the HRS architecture'. This system incorporates planning, scheduling and supervision of operations from a remote location, can integrate imagery and data from multiple assets, and will act as the focal point for communication and interaction between operators, robots and insitu personnel. The RAPID workbench includes several components or "clients" to perform its' functions. The Jet Propulsion Lab is programming the primary Mapping and Telemetry Canvas which will track and display all HRS 
elements and their respective locations, as well as provide a Graphical User Interface (GUI) for telemetry input and output. Johnson Space Center's Predictive Interactive Graphical Interface (PIGI) provides robustness of communication over intermediate time delays by calculating and predicting where an asset will be and displaying that path graphically so that preemptive control inputs can be made. Lastly, Ames Research Center is developing a software package called "Viz" to graphically display the configuration of each HRS asset in real-time using fully articulate 3D models.

In order to integrate the LSMS into the RAPID architecture, the command and monitoring interface currently used for manual control of the LSMS, and written in LABVIEW, must interface with the RAPID API. This involves setting up a bridge that takes a set of standardized parameters from the LSMS LABVIEW application, translating them via the bridge into RAPID protocol, and then

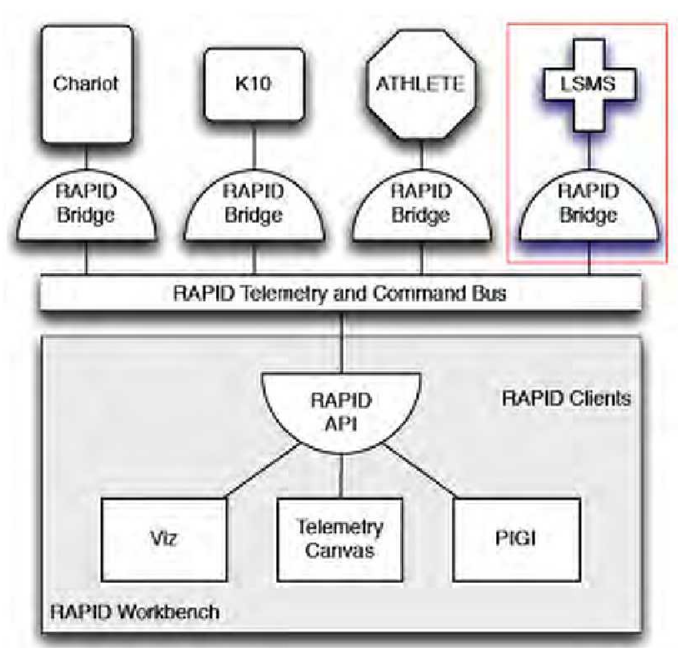

Figure 16. Diagram of RAPID command hierarchy and components.

receiving updated parameters back over the bridge (Figure 16). The "Message Set" of data from the LSMS includes: Status of power and current task being performed; Position - location and orientation; Joint Data - angle and motor velocity; and Picture Data - images and video. The return "Command Set" from RAPID includes: Get Status requests some or all of the above parameters; Robot Commands - change joint angles and velocities; and Camera Commands - orient cameras, take picture and/or video. To facilitate this transfer, an operator is provided a workbench environment called the ETDP Multi-Center Cockpit (MCC) which can send and receive these data sets to and from the assets and display all available telemetry simultaneously. Currently, the LSMS team is running initial trials with a preliminary software bridge provided by the RAPID team.

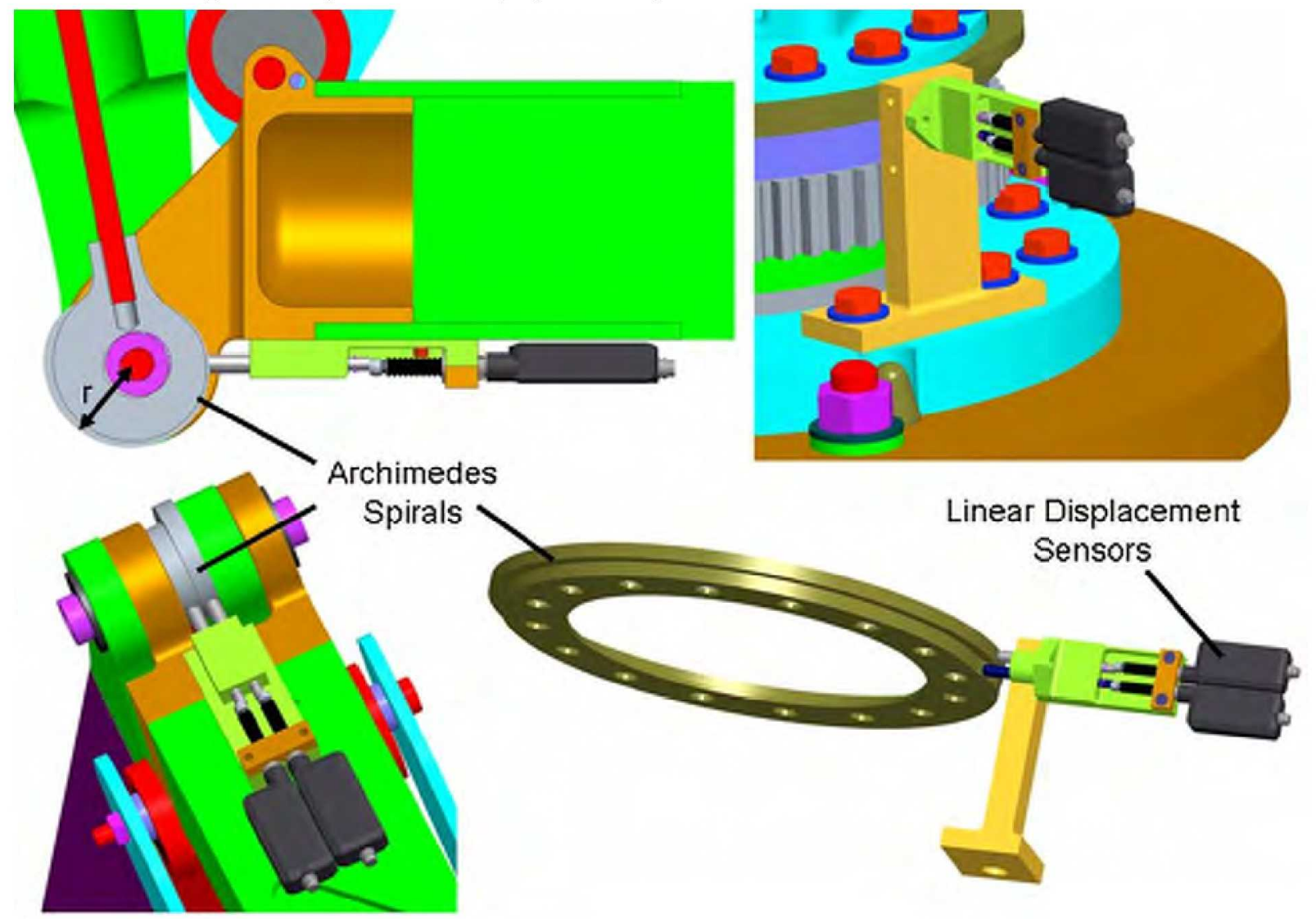

Figure 17. Modified LSMS joints with dual digital contact sensors.

American Institute of Aeronautics and Astronautics 
One of the key requirements in enabling automated and semi-automated control of the LSMS, and providing the telemetry required to graphically display the LSMS configuration, is the installation of joint angle sensors. Modified joint hardware has been designed for the waist, shoulder and elbow that allows the joints to use dual digital contact sensors to provide high precision absolute angle measurements (Figure 17). The design is based on incorporating an Archimedes spiral into the joint that defines a linear relationship between the radius of the contact surface and the joint angle (Equation 1).

$$
\begin{gathered}
r=R_{i}+(\theta / 360)\left(R_{o}-R_{i}\right) \\
\theta=360 \frac{\left(r-R_{i}\right)}{\left(R_{o}-R_{i}\right)}
\end{gathered}
$$

The angle can be determined for any measured $r$ (Figure 17), given the initial radius, $R_{i}$ and final radius, $R_{0}$ of the surface. Two identical spiral profiles are set adjacent and rotated relative to one another, providing two independent tracks for the two digital contact sensors at each joint. These dual tracks provide complete redundancy for the identical shoulder and elbow joints, and enable the waist joint to provide a continuous $360^{\circ}$ angle measurement. To obtain a continuous $360^{\circ}$ angle measurement for the waist requires a region on the track that transitions back from the maximum radius to the minimum radius. This results in there being two locations on the waist tracks where the measured radius is the same. However, rotation of the second track relative to the first, allows a unique value for the angle to be determined.

With the addition of joint angle sensors, and the integration of the LSMS into the RAPID architecture, remote semi-automated and automated control can be achieved. The inverse kinematics of the 3 degree-of-freedom system have been determined and will be used to calculate the joint angles required to place the wrist at a given location in 3D space. Currently the motor velocities are controlled independently in manual mode, but with the joint angles known, Cartesian positioning control will now be added as an option. This would allow, for example, the operator to use a single forward command, whereas previously, they would have had to drive the shoulder and elbow motors separately. The LSMS control program will be augmented in the near term to also provide a series of automated movements, such as engaging a lifting hook or moving to a chosen position. Future work will incorporate path planning and hazard avoidance using the onboard cameras to fully automate sequenced operations such as searching for, engaging and offloading payloads. Another development in the area of automated control of the LSMS includes studying the dynamics and control requirements for payloads suspended from a trolley that traverses the LSMS Arm and Forearm. In a second paper given at this conference ${ }^{10}$, optimal control techniques are applied to eliminate payload swinging motion at the conclusion of a LSMS maneuver. These models could allow increased speed of operations, and provide an increased level of precision and stability to all LSMS lifting maneuvers.

\section{Conclusions}

Devices for lifting, translating and precisely placing payloads, as well as performing regolith handling operations will be critical for a permanently occupied outpost on planetary surfaces such as the Moon and Mars. The first generation implementation of a new high performance, full scale, 3 degree-of-freedom device; the Lunar Surface Manipulation System (LSMS) has been designed, built and tested extensively in the laboratory and the field. This testing demonstrated conventional (crane type) payload handling configurations and operations of the LSMS. Because of the large investment required to develop and test a device for planetary surface operations, it is critical that the device be versatile and able to accomplish a variety of tasks. The range of motion, operations and the versatility of the LSMS has been greatly expanded to include; operations in forklift mode, side grappling of payloads, digging and positioning of loose regolith, and a variety of specialized end effectors. All of these have been described and demonstrate the versatility of the LSMS. The operational viability of the LSMS is strongly dependent on being able to reposition its base from its initial position on the lander onto mobility chassis as well as fixed locations around the lunar outpost. Preliminary concepts and designs for the major components of a secondgeneration LSMS design, which incorporates this self-offload capability, have been described. By incorporating design improvements and refinements, compared to the first generation design, the second generation will have longer reach and three times the payload capability, yet it's mass is predicted to be approximately equal to the current device. Currently, the LSMS is operated using joint velocity control with visual cues. Joint angle sensors, inverse kinematics and automated controls are being developed and incorporated into the current LSMS test-bed. The status of remote control operations, software and hardware development have also been reviewed. 


\section{References}

${ }^{1}$ Adinolfi, P. J.; and, Heinz, F. A. Jr.: Design Study of Special Purpose Systems For the Lunar Surface. NASA CR-61077, April 30, 1965.

${ }^{2}$ Eagle Engineering: Lunar Surface Construction and Assembly Equipment Study: Lunar Base Systems Study Task 5.3. NASA CR-172105, September, 1988.

3NASA: NASA's Exploration Systems Architecture Study, Final Report. NASA TM-2005-214062, 2005.

${ }^{4}$ Shapiro, H. I.; et. al.: Cranes and Derricks. McGraw-Hill Inc., 1980, $2^{\text {nd }}$ ed. 1991.

${ }^{5}$ Doggett, William R.; King, Bruce D.; Jones, Thomas C.; Dorsey, John T.; and Mikulas, Martin M.: Design and Field Test of a Mass Efficient Crane For Lunar Payload Handling and Inspection - The Lunar Surface Manipulation System. Presented at the AIAA Space 2008 Conference and Exposition, 9 - 11 September 2008, San Diego, California. Available as AIAA-2008-7635.

${ }^{6}$ Dorsey, John T.; Mikulas, Martin M.; and Doggett, William R.: Preliminary Structural Design Considerations and Mass Efficiencies for Lunar Surface Manipulator Concepts. Presented at the AIAA Space 2008 Conference and Exposition, 9 - 11 September 2008, San Diego, California. Available as AIAA-2008-7916.

${ }^{7}$ Wilcox, B. H.: ATHLETE; An Option for Mobile Lunar Landers. 2008 IEEE Aerospace Conference, Big Sky MT. pp 1 - 8.

${ }^{8}$ Doggett, W.; Dorsey, J.; Collins, T.; King, B.; and Mikulas, M.: A Versatile Lifting Device for Lunar Payload Handling, Inspection and Regolith Transport Operations. Proceedings of the Space Technology and Applications International Forum STAIF 2008. AIP Conference Proceedings Volume 969, Editor Mohamed S. El Genk, American Institute of Physics, 2008.

${ }^{9}$ Torres, R. J., Allan, M. B., Hirsh, R. L., "Rapid Workbench: Results of Collaboration Between Three NASA Centers in Commanding and Monitoring Lunar Assets," 2009 IEEE Aerospace Conference [submitted for publication], IEEE, New York, NY, Mar. 2009.

${ }^{10}$ Doggett, William R.; Roithmayr, Carlos M.; Dorsey, John T.; Jones, Thomas C.; King, Bruce D.; and Mikulas, Martin M.: Automation of a Versatile Crane (the LSMS) for Lunar Outpost Construction, Maintenance and Inspection. Presented at the AIAA Space 2009 Conference and Exposition, 14 - 17 September 2009, Pasadena, California. Available as AIAA-2009-6546. 